\title{
Prophylactic cranial irradiation in patients with small-cell lung cancer: the experience at the Institute of Oncology Ljubljana
}

\author{
Karmen Stanic, Viljem Kovac \\ Institute of Oncology, Department of Radiation Oncology, Ljubljana, Slovenia \\ Received 4 June 2010 \\ Accepted 14 June 2010 \\ Disclosure: No potential conflicts of interest were disclosed.
}

Correspondence to: Karmen Stanič, MD, MSc, Department of Radiation Oncology, Institute of Oncology Ljubljana, Zaloška 2, 1000 Ljubljana, Slovenia. Phone: +386 1587 9502; E-mail: kstanic@onko-i.si

Background. Prophylactic cranial irradiation (PCI) has been used in patients with small-cell lung cancer (SCLC) to reduce the incidence of brain metastases (BM) and thus increase overall survival. The aim of this retrospective study was to analyze the characteristics of patients with SCLC referred to the Institute of Oncology Ljubljana, their eligibility for $\mathrm{PCl}$, patterns of dissemination, and survival.

Patients and methods. Medical charts of 357 patients with SCLC, referred to the Institute of Oncology Ljubljana between January 2004 and December 2006, were reviewed to determine characteristics of patients chosen for PCl. The following data were collected: age, gender, performance status (PS), extent of the disease, smoking status, type of primary treatment with outcome, haematological and biochemical parameters, $\mathrm{PCl}$ use, and finally brain metastases (BM) status at diagnoses and after treatment.

Results. PCl was performed in 24 (6.7\%) of all patients. Six (25\%) patients developed brain metastases after they were treated with PCl. Brain was the only site of metastases in 4 patients, two progressed to multiple organs. Median overall survival of patients with PCl was 21.9 months, without PCl 12.13 months ( $p=0.004)$. From the collected data there were good prognostic factors: age under 65 years, limited disease (LD), performance status, normal levels of lactate dehydrogenase (LDH) and normal levels of C-reactive protein levels (CRP). Other prognostic factors did not show statistical significant values.

Conclusions. Survival of patients with LD, who have had PCl, was significantly better than those who had not. We decided to perform PCl in patients with LD, in those with complete or near complete response, and those with good performance status $(\geq 80$ ). We did not use PCl in extended disease (ED). The reason for that shall be addressed in the future. Doses for PCl were not uniform, therefore more standard approach should be considered.

Key words; small-cell lung cancer, brain metastases, prophylactic cranial irradiation

\section{Introduction}

Small-cell lung cancer (SCLC) expresses aggressive behaviour. Combined treatment with chemotherapy and radiotherapy provides response rates between $50-85 \%$ in limited disease (LD). Local recurrence rate decreases with combined treatment; however, brain metastases (BM) become the most common site of relapse. Brain metastases are present in about $20 \%$ of patients at the time of diagnosis, but in autopsy findings the rate reached over $50 \%{ }^{1,2}$ As in other cancers, in clinical practice BM are diagnosed with computer tomography (CT), less common with magnetic resonance imaging $(\mathrm{MRI})^{3,4}$; and all are treated with radiotherapy. ${ }^{5}$

In the early 1970s, prophylactic cranial irradiation (PCI) has been proposed to improve overall survival, because it is well known that central nervous system is relatively refractory to chemotherapy due to the blood-brain barrier. In the 1980s and 1990s there were many prospective studies conducted to investigate the use of PCI; however, only after the publication of two meta-analysis reporting improvement, both, in overall survival and dis- 
ease free survival, PCI became a part of the standard treatment in SCLC. The first meta-analysis by Auperin et al. in 1999 reported the 5.4\% increase in the rate of survival at three years as well as the increased rate of disease-free survival. ${ }^{6}$ Meert et al. in meta-analysis in 2001 composed 12 randomized trials and reported a hazard ratio of 0.48 for the incidence of brain metastases after PCI. ${ }^{7}$

Recent studies suggest that patients in extensive disease setting could also benefit from PCI. 8,9

The aim of this analysis was to review the use of PCI, to analyze the characteristics of patients with SCLC, referred to the Institute of Oncology Ljubljana, eligibility for PCI, patterns of dissemination, and survival.

\section{Patients and methods}

Cancer Registry of Republic of Slovenia reported 574 newly diagnosed patients with SCLC in the period between 2004 and 2006. ${ }^{10-12}$ Three hundred fifty seven patients $(62.19 \%)$, reviewed in this analysis, were referred for further treatment to the Institute of Oncology Ljubljana, mainly from University Clinic of Respiratory and Allergic Diseases Golnik and University Clinical Centre Maribor. One patient refused all types of further diagnostic procedures and treatments and was excluded from further evaluation.

The following data were collected: gender, age, extent of disease, performance status, smoking status, presence of other malignancies, starting serum levels of haemoglobin $(\mathrm{Hb})$, lactate dehydrogenase $(\mathrm{LDH})$ and $\mathrm{C}$-reactive protein $(\mathrm{CRP})$, type of treatment, response to treatment, $\mathrm{PCI}$ information, pattern of dissemination, BM status at diagnoses and after the treatment.

LD included patients with lesions confined to ipsilateral hemitorax, and regional and supra-clavicular lymph nodes. Extended disease (ED) was characterized by an evident and/or proven metastases.

Irradiation was performed at the Institute of Oncology Ljubljana; however, chemotherapy was delivered either at Institute of Oncology Ljubljana (189 patients), University Clinic of Respiratory and Allergic Diseases Golnik (123 patients) or at University Clinical Centre Maribor (29 patients). Twenty one referred patients received no treatment due to poor performance status at presentation at the Institute or due to deterioration of disease during the waiting time for therapy.

Treatment responses were evaluated according to the data available in medical charts as judged
TABLE 1. Characteristics of patients

\begin{tabular}{|c|c|c|}
\hline Number of patients & 356 & $\%$ \\
\hline \multicolumn{3}{|l|}{ Gender } \\
\hline Male & 270 & 75.84 \\
\hline Female & 86 & 24.15 \\
\hline Age (years) & $\begin{array}{c}61.86 \\
(40-83)\end{array}$ & \\
\hline \multicolumn{3}{|l|}{ Clinical stage } \\
\hline Limited disease & 167 & 46.10 \\
\hline Extended disease & 188 & 52.80 \\
\hline No data available & 1 & 0.2 \\
\hline \multicolumn{3}{|l|}{ Performance status (Karnofsky) } \\
\hline$>80$ & 71 & 19.9 \\
\hline $60-80$ & 196 & 55.05 \\
\hline$<60$ & 29 & 8.14 \\
\hline No data available & 60 & 16.85 \\
\hline \multicolumn{3}{|l|}{ Lactate dehydrogenase (LDH) } \\
\hline Normal $\quad(\leq 4.23 \mu \mathrm{kat} / \mathrm{L})$ & 158 & 44.38 \\
\hline Elevated $\quad(>4.23 \mu \mathrm{kat} / \mathrm{L})$ & 102 & 28.65 \\
\hline No data available & 96 & 26.96 \\
\hline \multicolumn{3}{|l|}{ C-reactive protein levels (CRP) } \\
\hline Normal $\quad(\leq 15 \mathrm{mg} / \mathrm{L})$ & 122 & 34.26 \\
\hline Elevated (> $15 \mathrm{mg} / \mathrm{L})$ & 132 & 37.07 \\
\hline No data available & 102 & 28.65 \\
\hline \multicolumn{3}{|l|}{ Haemoglobin (Hb) } \\
\hline$<120$ (g/L) & 86 & 24.15 \\
\hline$\geq 120$ (g/L) & 186 & 52.24 \\
\hline No data available & 84 & 23.59 \\
\hline \multicolumn{3}{|l|}{ Smoking status } \\
\hline Non smokers & 8 & 2.24 \\
\hline Smokers & 163 & 45.78 \\
\hline Ex smokers & 84 & 23.59 \\
\hline No data available & 101 & 28.37 \\
\hline Other malignancies & 36 & 10.11 \\
\hline synchronic & 6 & 1.6 \\
\hline metachronic & 30 & 8.4 \\
\hline Brain metastases (BM) as the only site & 66 & 18.53 \\
\hline BM at diagnoses & 37 & 10.39 \\
\hline BM after primary treatment & 29 & 8.14 \\
\hline
\end{tabular}




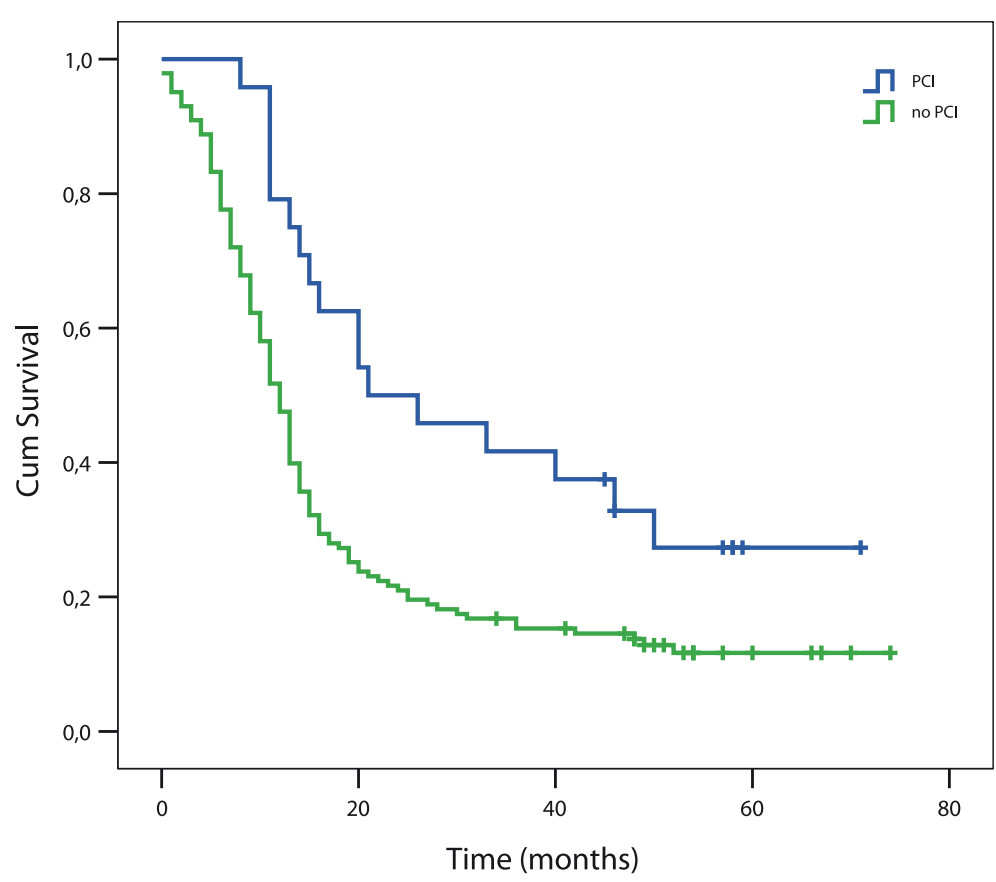

FIGURE 1. Survival of patients with prophylactic cranial irradiation (PCI) and without $\mathrm{PCl}(p=0.004)$. by radiation oncologist, based either on X-ray or $\mathrm{CT}$ examination during the follow-up. Some of the complete responses (CR) were also confirmed bronchoscopically.

PCI patients were irradiated on Cobalt unit with 1.25 MV or on linear accelerator with 5 or $6 \mathrm{MV}$ photon beams for 5 days per week, once daily. The irradiated field involved whole brain using two opposed lateral fields.

As established the biologic effectiveness of radiation schedules depends on total dose and dose per fraction. The Equivalent Dose in 2-Gy fraction (EQD2) was calculated with the equation as derived from the linear-quadratic model

$E Q D 2=D x[(d+\alpha / \beta) / 2 \mathrm{~Gy}+\alpha / \beta)]$,

where $\mathrm{D}=$ total dose, $\mathrm{d}=$ dose per fraction, $\alpha=$ linear (first-order dose-dependent) component of cell killing, $\beta=$ quadratic (second-order dose dependent) component of cell killing, $\alpha / \beta$-ratio = the dose where both components are equal. In analysis $\alpha / \beta$-ratio of 10 Gy was used to calculate the biological effectiveness of radiation for tumor-cells and $\alpha / \beta$-ratio of $3 \mathrm{~Gy}$ was used for normal tissue. ${ }^{13}$

\section{Statistics}

Statistical analysis was performed using personal computer and software statistical package SPSS, version 13 (SPSS Inc., USA).
The overall survival time was defined as the time from diagnosis to death or until the end of follow up period on April $1^{\text {st }} 2010$. The number of surviving patients was confirmed at this date.

Time to progression to brain was defined as time from diagnosis to confirmation of brain metastases by image diagnostics. For patients with PCI time to development of brain metastases was calculated also for period after completion of PCI to confirmation of brain metastases by image diagnostic.

Survival was calculated according to KaplanMeier's method and differences were confirmed by the log-rank test. Independent variables that appeared statistically significant on univariate analysis were tested by multivariate Cox regression analysis model.

\section{Results}

Between January 2004 and December 2006 institutions referred 357 patients with SCLC for further treatment to the Institute of Oncology; 356 were evaluable. Characteristics of patients are detailed in Table 1.

Median age at diagnosis was 61.86 years (40-83); majority were male $(76 \%)$.

LD was present in $46 \%$ of patients, ED in $53 \%$. Performance status, expressed in numbers of the Karnofsky scale, could be collected for majority of patients; however, for $17 \%$ patients only descriptions of status could be found in medical records. Majority of patients were smokers (46\%). For exsmokers $(24 \%)$ qualified patients who stopped smoking at least one year prior to diagnosis. Only $8(2 \%)$ patients were non-smokers; for $28 \%$ of patients data could not be retrieved from the medical records. Thirty six $(10 \%)$ patients have had second malignancy, 6 synchronously and 30 before SCLC. Majority have had head and neck tumours (13), non-SCLC (6), skin tumours including melanoma (6), breast tumours (3), lymphoma (2), prostate carcinoma (2) and other types (3). Two hundred twenty six $(63.48 \%)$ patients have had CT or MR imaging during their diagnostic work up procedure - there were 15 (4.2\%) without it; for 113 (31.74\%) patients, data were not available.

The type of treatment and outcome are presented in Table 2. Majority of patients were treated with chemotherapy and irradiation. Chemotherapy as the only treatment was delivered mainly to patients with ED and 13 patients were irradiated only. Four patients underwent surgery and completed chemotherapy. Treatment resulted in 9 complete 
TABLE 2. Treatment characteristics and outcome

\begin{tabular}{lcccccc}
\hline & CR & PR & SD & PD & unknown & All \\
\hline Chemotherapy & 1 & 22 & 33 & 22 & 67 & 145 \\
Chemotherapy and radiotherapy & 6 & 64 & 37 & 13 & 53 & 173 \\
Radiotherapy & 0 & 3 & 1 & 0 & 9 & 13 \\
Surgery and chemotherapy & 2 & 1 & 0 & 0 & 1 & 4 \\
No therapy & & & & & & 21 \\
\hline
\end{tabular}

$C R=$ complete response,$P R=$ partial response; $S D=$ stable disease; $P D=$ progressive disease

responses (CR), 90 partial responses (PR), 71 stable diseases (SD) and 35 progressive diseases (PD). For 150 patients evaluation was not appropriately recorded.

Metastases to brain as the only site of dissemination was present in 37 patients $(10.39 \%)$ at the time of diagnoses. Twenty-nine patients $(8.14 \%)$ progressed after primary treatment.

Radiotherapy oncologists proposed PCI to 30 patients, whom they considered eligible, but 6 have refused it. 24 patients (6\%) received PCI (20 male and 4 female), mean age of patients with PCI was 53.54 years. Characteristics of patients who received PCI are presented in Table 3. All patients with PCI had LD, statistical significant better performance status, were younger and smokers or ex smokers, only one patient had previous other malignancy.

Dose schedules of PCI were not uniform and are presented in Table 4 . No trends in difference of $\mathrm{BM}$ frequency with increased biological equivalent dose (calculated as EQD2) received at PCI could be detected.

After PCI 6 (25\%) patients developed brain metastases, in 4 patients brain was the only site of metastases, in 2 patients the disease progressed to multiple organs. In 4 out of 6 patients additional cranial irradiation was performed; in 2 patients the disease progressed while waiting for radiotherapy.

Brain was the first site of metastases in 29 patients with LD SCLC; among them 4 patients have had PCI and 25 patients were without PCI, including also 3 patients that have refused PCI. BM were present in 37 patients at the time of diagnosis (ED), 48 patients developed BM later. Overall incidence of $\mathrm{BM}$ in our population was therefore $32 \%$.

The mean time to development of $\mathrm{BM}$ as a single site of progression for patients with PCI was 32.7 months (14.59-58.62). Mean time to development of $\mathrm{BM}$ as single site of progression for 25 other patients with LD who did not have PCI was 10.75 months (0.72-30.1). The difference was statistically significant $(\mathrm{p}<0.001)$.
The median overall survival (OS) for all 356 patients with SCLC included in analyses was 9.4 months (95\% CI; 8.37 - 10.44)

The median OS of 167 patients presented with LD SCLC was 13.34 months (95\% CI; 12.17-14.51). Median OS of patients with PCI was 21.9 months (95\% CI; 6.31-37.48), for those without PCI was 12.13 months (95\%CI; 10.69-14.51). The difference was statistically significant (log rank, $\mathrm{p}=0.004$ ) (Figure 1). On our cut-off date on April $1^{\text {st }} 2010$ there were 28 patients still alive, 7 of them have received PCI.

Univariate analysis including all patients with SCLC showed statistically significant better survival in patients with age $<65$ years, PS $>80$, normal LDH and CRP levels, those with PCI and LD and, surprisingly, smokers. In multivariate analysis only LD ( $<<0.0001, \mathrm{HR}=0.49,95 \%$ CI $0.332-0.722)$ and PS ( $p=0.03, \mathrm{HR}=0.63,95 \%$ CI 0.419-0.973) were identified as independent prognostic factors. Since PCI was only performed in patients with LD, separate analysis was performed for this population. In univariate analysis age $<65$ years, PS > 80 and PCI showed statistically significant better survival. Multivariate analysis identified only age $(\mathrm{p}=0.001)$ and PS $(\mathrm{p}=0.008)$ as independent prognostic variables.

\section{Discussion}

PCI has been used in patients with LD SCLC to reduce the incidence of $\mathrm{BM}$ and increase overall survival, however reports suggest it should be used also in patients with ED SCLC. In our institution only patients with LD received PCI (14.37\%). Retrospective reports in the literature mention about $8 \%{ }^{14}$

Standard treatment consists of combination of chemotherapy and thoracic irradiation of the site of primary tumour. ${ }^{15}$ Combined treatment was delivered to 129 (77.24\%) patients with LD SCLC, al- 
TABLE 3. Characteristics of patients with prophylactic cranial irradiation

\begin{tabular}{|c|c|c|}
\hline \multirow{2}{*}{ Number of patients } & \multicolumn{2}{|r|}{$\%$} \\
\hline & 24 & 6.7 \\
\hline \multicolumn{3}{|l|}{ Gender } \\
\hline Male & 20 & 83.33 \\
\hline Female & 4 & 16.66 \\
\hline \multirow[t]{2}{*}{ Age (years) } & 53.54 & \\
\hline & $(43-73)$ & \\
\hline \multicolumn{3}{|l|}{ Performance status (Karnofsky) } \\
\hline$\geq 90$ & 6 & 25 \\
\hline 80 & 16 & 66.66 \\
\hline Data not available & 2 & 8.3 \\
\hline \multicolumn{3}{|l|}{ Smoking status } \\
\hline Non smokers & 0 & 0 \\
\hline Smokers & 16 & 66.66 \\
\hline Ex smokers & 4 & 16.66 \\
\hline No data available & 4 & 16.66 \\
\hline Other malignancies & 1 & 4.1 \\
\hline synchronic & 0 & 0 \\
\hline metachronic & 1 & 4.1 \\
\hline \multicolumn{3}{|l|}{ Lactate dehydrogenase (LDH) } \\
\hline Normal $\quad(<4.23 \mu \mathrm{kat} / \mathrm{L})$ & 14 & 58.33 \\
\hline Elevated $\quad(>4.24 \mu \mathrm{kat} / \mathrm{L})$ & 2 & 8.3 \\
\hline Data not available & 8 & 33.33 \\
\hline \multicolumn{3}{|l|}{ C-reactive protein levels (CRP) } \\
\hline Normal $\quad(<15 \mathrm{mg} / \mathrm{L})$ & 10 & 41.66 \\
\hline Elevated (> $15 \mathrm{mg} / \mathrm{L})$ & 8 & 33.33 \\
\hline Data not available & 6 & 25 \\
\hline \multicolumn{3}{|l|}{ Haemoglobin $(\mathrm{Hb})$} \\
\hline$<120(\mathrm{~g} / \mathrm{L})$ & 14 & 58.33 \\
\hline$>120(\mathrm{~g} / \mathrm{L})$ & 3 & 12.5 \\
\hline Data not available & 6 & 25 \\
\hline \multicolumn{3}{|l|}{ Response to primary treatment } \\
\hline $\mathrm{CR}$ & 5 & 20.83 \\
\hline$P R$ & 17 & 70.83 \\
\hline Data not available & 2 & 8.33 \\
\hline Brain metastases & 6 & 25 \\
\hline As only site of progress & 4 & 16.66 \\
\hline In multiple organ progress & 2 & 8.3 \\
\hline
\end{tabular}

$C R=$ complete response, $P R=$ partial response so the majority of PCI patients in our review were given this treatment; one patient received only chemotherapy and was referred from another institution and one patient underwent only surgery and chemotherapy prior to PCI.

PCI is eligible in patients who achieve complete or near complete response after treatment of primary tumour. In our review only 69 (41.3\%) patients in LD group met this criteria; however, data for 60 patients from the same group of LD were not available - the majority of them completed treatment in other institutions and were evaluated there. In group of patients with PCI 5 CR and 17 PR (near $\mathrm{CR}$ ) were observed, for 2 patients appropriate data were not available in medical records.

None of our patients with ED SCLC received PCI, although 30 had PR responses, however, there were no CR. There are reports that suggest considering PCI also in patients who respond to first line chemotherapy. ${ }^{16}$

Patients who received PCI were younger than SCLC population studied. Radiation oncologists have chosen for PCI patients with the Karnofsky performance status (PS) of 80 or higher. This is in accordance with performance status patient's selection in prospective studies. ${ }^{17}$ The majority of patients were heavy smokers as was expected in population of patients with SCLC. ${ }^{18}$ Heavy smokers have comorbidities and therefore usually lower performance status, making them less likely candidates for radical treatment and also for PCI. ${ }^{19}$ Bremnes et al. reported gender, extent of disease, $\mathrm{PS}, \mathrm{Hb}$ levels and $\mathrm{LDH}$ to be independent prognostic factors. ${ }^{20}$ In our analyses only age $<65$ years and PS were independent factors of survival in multivariate analysis.

Doses of PCI in our review were not uniform. Meta analysis suggested trend towards increased reduction of BM rate with increased dose, however, prospective study exploring high versus low dose in PCI found no reduction in total incidence of $\mathrm{BM}$, but there was increased mortality with higher doses. ${ }^{6}$ Therefore a dose of 25 Gy was suggested to be the standard care in LD SCLC. ${ }^{16,21}$ All our patients received biological equivalent doses higher than $25 \mathrm{~Gy}$, but no increased mortality nor difference in frequency of BM according to the biological equivalent dose could be detected. The number of analysed PCI patients was small; therefore no conclusions could have been made.

According to our review 4 patients refused PCI. Details of this refusal were not described in our medical records. We could assume that the fear of possible side effects might have been one of the 
TABLE 4. Irradiation doses that were applied as prophylactic cranial irradiation

\begin{tabular}{llcccc}
\hline & Dose schedule & $\begin{array}{c}\text { EDQ2 } \\
\mathbf{a} / \boldsymbol{\beta}=10\end{array}$ & $\begin{array}{c}\text { EDQ2 } \\
\mathbf{a} / \boldsymbol{\beta}=3\end{array}$ & $\begin{array}{c}\text { Number of pa- } \\
\text { tients treated }\end{array}$ & $\begin{array}{c}\text { Number of pa- } \\
\text { tients alive }\end{array}$ \\
\hline 1 & $14 \times 2.0 \mathrm{~Gy}=28.0 \mathrm{~Gy}$ & 28.0 & 28.0 & 3 & 0 \\
2 & $15 \times 2.0 \mathrm{~Gy}=30.0 \mathrm{~Gy}$ & 30.0 & 30.0 & 2 & 2 \\
3 & $17 \times 2.0 \mathrm{~Gy}=35.0 \mathrm{~Gy}$ & 35.0 & 35.0 & 1 & 0 \\
4 & $12 \times 2.2 \mathrm{~Gy}=26.4 \mathrm{~Gy}$ & 26.84 & 27.45 & 3 & 1 \\
5 & $13 \times 2.2 \mathrm{~Gy}=28.6 \mathrm{~Gy}$ & 29.07 & 29.74 & 1 & 1 \\
6 & $14 \times 2.2 \mathrm{~Gy}=30.8 \mathrm{~Gy}$ & 31.31 & 32.03 & 1 & 2 \\
7 & $12 \times 2.5 \mathrm{~Gy}=30.0 \mathrm{~Gy}$ & 31.25 & 33.0 & 4 & 1 \\
8 & $14 \times 2.5 \mathrm{~Gy}=35.0 \mathrm{~Gy}$ & 36.45 & 38.5 & 5 & 4 \\
9
\end{tabular}

$E D Q 2=$ Equivalent Dose in 2-Gy fraction

reasons. Several studies reported neurological impairment or abnormalities potentially related was PCI.9,22-26 Acute toxicity consisted mostly of alopecia, headache, fatigue, nausea and vomiting and was usually manageable on outpatient basis. Long term toxicities such as memory loss, intellectual impairment, demenca, ataxia or seizures could be of great concern.

The incidence of $\mathrm{BM}$ as the first site of relapse at 5 years have been reported to be $37 \%$ in a group of patients not receiving $\mathrm{PCI}$ and $20 \%$ in PCI group. ${ }^{17}$ However, patients in the study reported had only CR and included also a proportion of ED SCLC. Recent retrospective report indicated 25\% incidence of development of BM after PCI, however, number of patients was again small. ${ }^{27}$ The same proportion of patients developed BM also in our series.

There are still doubts among radiation oncologists about using PCI, although even cost effectiveness and quality of life studies beside studies confirming improvement in BM control, OS and DFS have been published. ${ }^{28}$ There are decision making tools and practice guidelines available, but judgment of radiation oncologist should prevail specially in cases of near CR. ${ }^{29-31}$

\section{Conclusions}

Our analysis confirmed increased median survival time and decreased incidence for BM in patients with PCI.

Our policy of treatment was to perform PCI in patients with LD and good performance status, the two variables that independently showed better survival. Adding PCI in these patients setting fur- ther increased survival. Possibilities of using PCI also in ED SCLC in our institution should be further explored in the future. Doses for PCI were not uniform therefore more standard approach should be considered.

\section{References}

1. Hirsch FR, Paulson $\mathrm{OB}$, Hansen $\mathrm{HH}$, Larsen SO. Intracranial metastases in small cell carcinoma of the lung. Prognostic aspects. Cancer 1983; 51: 529-33.

2. Hirsch FR, Paulson $\mathrm{OB}$, Hansen $\mathrm{HH}$, Vraa-Jensen J. Intracranial metastases in small cell carcinoma of the lung: correlation of clinical and autopsy findings. Cancer 1982; 50: 2433-7.

3. Oztekin O, Savas R, Ozan E, Apaydin M, Yasar O, Adibelli ZH, et al. Pineal gland metastasis of auricular squamous cell carcinoma: an unusual case and literature review. Radiol Oncol 2009; 43: 175-9.

4. Bisof V, Juretic A, Saric N, Melada A, Perkovic Z, Rados M, et al. Pituitary metastasis of renal cell carcinoma: a case report. Radiol Oncol 2008; 42: 225-31.

5. Strojan P. Role of radiotherapy in melanoma management. Radiol Oncol 2010; 44: 1-12.

6. Auperin A, Arriagada R, Pignon JP, Le Péchoux C, Gregor A, Stephens RJ, et al. Prophylactic cranial irradiation for patients with small-cell lung cancer in complete remission. Prophylactic Cranial Irradiation Overview Collaborative Group. N Engl J Med 1999; 341: 476-84.

7. Meert AP, Paesmans M, Berghmans T, Martin B, Mascaux C, Vallot F, et al. Prophylactic cranial irradiation in small cell lung cancer: a systematic review of the literature with meta-analysis. BMC Cancer 2001; 1: 5 .

8. Slotman B, Faivre-Finn C, Kramer G, Rankin E, Snee M, Hatton M, et al. Prophylactic cranial irradiation in extensive small-cell lung cancer. $N$ Engl J Med 2007; 357: 664-72.

9. Slotman BJ, Mauer ME, Bottomley A, Faivre-Finn C, Kramer GW, Rankin $E M$, et al. Prophylactic cranial irradiation in extensive disease small-cell lung cancer: short-term health-related quality of life and patient reported symptoms: results of an international Phase III randomized controlled trial by the EORTC Radiation Oncology and Lung Cancer Groups. J Clin Oncol 2009; 27: 78-84.

10. Cancer Registry of Republic of Slovenia. Cancer incidence in Slovenia 2004. Report No.46. Ljubljana: Institute of Oncology Ljubljana, Cancer Registry of Republic of Slovenia; 2007. 
11. Cancer Registry of Republic of Slovenia. Cancer incidence in Slovenia 2005 Report No.47. Ljubljana: Institute of Oncology Ljubljana, Cancer Registry of Republic of Slovenia; 2008.

12. Cancer Registry of Republic of Slovenia. Cancer Incidence in Slovenia 2006 Report No 48. Ljubljana: Institute of Oncology Ljubljana, Cancer Registry of Republic of Slovenia; 2009.

13. Joiner MC, Bentzen SM. Fractionation: the linear-quadratic approach. In: Joiner M, van der Kogel A, eds. Basic Clinical Radiobiology. Great Britain: Hodder Arnold; 2009. p. 102-19.

14. Patel S, Macdonald OK, Suntharalingam M. Evaluation of the use of prophylactic cranial irradiation in small cell lung cancer. Cancer 2009; 15: 842-50.

15. Puglisi M, Dolly S, Faria A, Myerson JS, Popat S, O'Brien ME. Treatment options for small cell lung cancer - do we have more choice? Br J Cancer 2010; 102: 629-38.

16. Blanchard P, Le Pechoux C. Prophylactic cranial irradiation in lung cancer Curr Opin Oncol 2010. 22: 94-101.

17. Arriagada R, Le Chevalier T, Riviere A, Chomy P, Monnet I, Bardet E, et al. Patterns of failure after prophylactic cranial irradiation in small-cell lung cancer: analysis of 505 randomized patients. Ann Oncol 2010; 3: 748-54.

18. Debevec $L$, Jerič $T$, Kovač $V$, Bitenc $M$, Sok $M$. Is there any progress in routine management of lung cancer patients? A comparative analysis of an institution in 1996 and 2006. Radiol Oncol 2009; 43: 47-53.

19. Debevec L. Influence of comorbidity on the survival of patients with lung cancer. Zdrav Vestn 2007; 6: 81-5.

20. Bremnes RM, Sundstrom S, Aaseb $\varnothing$ U, Kaasa S, Hatlevoll R, Aamdal S; Norweigian Lung Cancer Study Group. The value of prognostic factors in small cell lung cancer: results from a randomised multicenter study with minimum 5 year follow-up. Lung Cancer 2003; 39: 303-13.

21. Le Pechoux C, Dunant A, Senan S, Wolfson A, Quoix E, Faivre-Finn C, et al. Standard-dose versus higher-dose prophylactic cranial irradiation $(\mathrm{PCI})$ in patients with limited-stage small-cell lung cancer in complete remission after chemotherapy and thoracic radiotherapy (PCI 99-01, EORTC 2200308004, RTOG 0212, and IFCT 99-01): a randomised clinical trial. Lancet Oncol 2009; 10: 467-74.

22. Komaki R, Meyers CA, Shin DM, Garden AS, Byrne K, Nickens JA, et al. Evaluation of cognitive function in patients with limited small cell lung cancer prior to and shortly following prophylactic cranial irradiation. Int J Radiat Oncol Biol Phys 1995; 33: 179-82.

23. Grosshans DR, Meyers CA, Allen PK, Davenport SD, Komaki R. Neurocognitive function in patients with small cell lung cancer: effect of prophylactic cranial irradiation. Cancer 2008; 112: 589-95.

24. van Oosterhout AG, Boon PJ, Houx PJ, ten Velde GP, Twijnstra A. Follow-up of cognitive functioning in patients with small cell lung cancer. Int J Radiat Oncol Biol Phys 1995; 31: 911-4.

25. Welzel G, Fleckenstein K, Schaefer J, Hermann B, Kraus-Tiefenbacher U, Mai SK, et al. Memory function before and after whole brain radiotherapy in patients with and without brain metastases. Int J Radiat Oncol Biol Phys 2008. 72: 1311-8.

26. Johnson BE, Patronas N, Hayes W, Grayson J, Becker B, Gnepp D, et al. Neurologic, computed cranial tomographic, and magnetic resonance imaging abnormalities in patients with small-cell lung cancer: further follow-up of 6- to 13-year survivors. J Clin Oncol 1990. 8: 48-56.

27. Alshehadat S, Sahmoun AE. Prophylactic cranial irradiation in limited-stage small-cell lung cancer: a retrospective analysis. Clin Adv Hematol Oncol 2004; 2: 397-400.

28. Tai TH, Yu E, Dickof P, Tonita J, Ago T, Skarsgard D, et al. Prophylactic cranial irradiation revisited: cost-effectiveness and quality of life in small-cell lung cancer. Int J Radiat Oncol Biol Phys 2002; 52: 68-74.

29. Kotalik J, Yu E, Markman BR; Cancer Ontario Practice Guidelines Initiative Lung Cancer Disease Site Group. Practice guideline on prophylactic cranial irradiation in small-cell lung cancer. Int J Radiat Oncol Biol Phys 2001. 50: 309-16.

30. Bohrer M, Wenz F. Prophylactic cranial irradiation in limited-disease smallcell lung cancer - why, when, how much? Onkologie 2002. 25: 66-8.

31. Lee JJ, Bekele BN, Zhou X, Cantor SB, Komaki R, Lee JS. Decision analysis for prophylactic cranial irradiation for patients with small-cell lung cancer. J Clin Oncol 2006; 24: 3597-603. 